\title{
COVID-19 in a Patient with Chronic Lymphocytic Leukaemia with Pseudohypoxemia
}

\author{
Orivaldo Alves Barbosa ${ }^{1,2}$, Talita Guimarães Andrade², Maria Danielly de Almeida Sousa², José Walter Correia ${ }^{3}$ \\ ${ }^{1}$ Hospital Geral Dr. César Cals, Fortaleza /Ceará, Brazil \\ ${ }^{2}$ Department of Medicine, Christus University Center (UNICHRISTUS), Fortaleza /Ceará, Brazil \\ ${ }^{3}$ Department of Internal Medicine, Hospital Geral Dr. César Cals, Fortaleza /Ceará, Brazil
}

Doi: 10.12890/2020_001763 - European Journal of Case Reports in Internal Medicine - ๔ EFIM 2020

Received: 29/05/2020

Accepted: 02/06/2020

Published: 11/06/2020

How to cite this article: Alves Barbosa O, Guimarães Andrade T, de Almeida Sousa MD, Correi JW. COVID-19 in a patient with chronic lymphocytic leukaemia with pseudohypoxemia. EJCRIM 2020;7: doi:10.12890/2020_001763.

Conflicts of Interests: The Authors declare that there are no competing interests.

This article is licensed under a Commons Attribution Non-Commercial 4.0 License

\section{ABSTRACT}

Infection with SARS-CoV-2 causes critical disease in approximately $5 \%$ of affected patients, particularly the elderly, hypertensive, obese and immunocompromised. Patients with haematological cancer, including chronic lymphocytic leukaemia (CLL), are particularly at risk of complications. Very rarely, patients with extreme leukocytosis may develop spurious hypoxemia, or pseudohypoxemia, which confuses the diagnosis of complications and can lead to intervention errors. We report the case of a patient with CLL, severe infection with SARS-CoV-2 and pseudohypoxemia.

\section{LEARNING POINTS}

- Patients with haematological neoplasms are susceptible to viral, bacterial and fungal infections, and are thus at risk of COVID-19.

- Patients with chronic lymphocytic leukaemia may rarely, due to a high lymphocyte count, present with spurious, or in vitro, hypoxemia.

- The clinician must identify and properly treat such cases to prevent any unnecessary treatments and their complications.

\section{KEYWORDS}

Chronic lymphocytic leukaemia, COVID-19, coronavirus, pseudohypoxemia, sepsis

\section{INTRODUCTION}

A novel coronavirus was isolated following a series of viral pneumonia cases in late 2019 in Wuhan, China and notified in January 2020. This new virus, now called severe acute respiratory syndrome coronavirus 2 (SARS-CoV-2) causes an acute respiratory illness, coronavirus disease 19 (COVID-19) ${ }^{[1]}$.

There are few data on the risk of developing COVID-19 in people hospitalized with haematological cancers. Most such patients are either given anticancer drugs that suppress bone marrow function or have immune-system cancers, and are at high risk of both community- and hospital-acquired infection. A Chinese survey reported a 10\% case rate of COVID-19 in 128 people hospitalized with haematological cancer in Wuhan, higher than that recorded in those with solid cancers $\left(<1 \%{ }^{[2]}\right.$. Chronic lymphocytic leukaemia (CLL), a mature B-cell neoplasm characterized by progressive accumulation of monoclonal B-lymphocytes, is the most common form of leukaemia in adults. The hallmark of this disease is lymphocytosis in peripheral blood, with various types of cytopenia, immunoglobulin deficiency with recurrent infection, splenomegaly and lymphadenopathy. There are only a few reported cases of SARS-CoV-2 infection in this group of patients. A rare complication in these patients is spurious hypoxemia because of the high number of lymphocytes in vitro with elevated dissolved 
oxygen consumption in blood samples. Blood gas measurement shows deceptively low blood oxygen pressure $\left(\mathrm{PaO}_{2}\right)$ levels, with normal oxygen saturation $\left(\mathrm{SaO}_{2}\right)$. This leads potentially to diagnosis and therapeutic errors, such as needless procedures and oxygen-induced toxicity. We report a rare case of pseudohypoxemia in a patient with COVID-19 and CLL.

\section{CASE DESCRIPTION}

A patient hospitalised with CLL, which had been diagnosed by flow cytometry in 2015, presented in mid-March 2020 with fever, a sore throat, dry cough and dyspnoea. The dyspnoea worsened after 4 days and the patient was admitted to an isolation room in an intensive care unit due to suspicion of COVID-19.

Chest tomography showed bilateral ground-glass opacities with multifocal confluent mosaic attenuation areas, involving much of the lung parenchyma (Fig. 1). A nasal swab was positive for SARS-CoV-2 on RT-PCR testing.

Due to worsening respiratory symptoms, decreased blood oxygenation and enlargement of the infiltrate on radiology (Fig. 2), orotracheal intubation was performed and methylprednisolone $60 \mathrm{mg} /$ day, antibiotics (piperacillin+tazobactam $18 \mathrm{~g} /$ day, azithromycin $500 \mathrm{mg} / \mathrm{day}$ and linezolid $1200 \mathrm{mg} / \mathrm{day}$ ) and hydroxychloroquine $400 \mathrm{mg} /$ day were administered. Lung protective ventilation was initiated, maintaining a plate pressure of $<30 \mathrm{mmHg}$ and a distension pressure of $<15 \mathrm{mmHg}$.
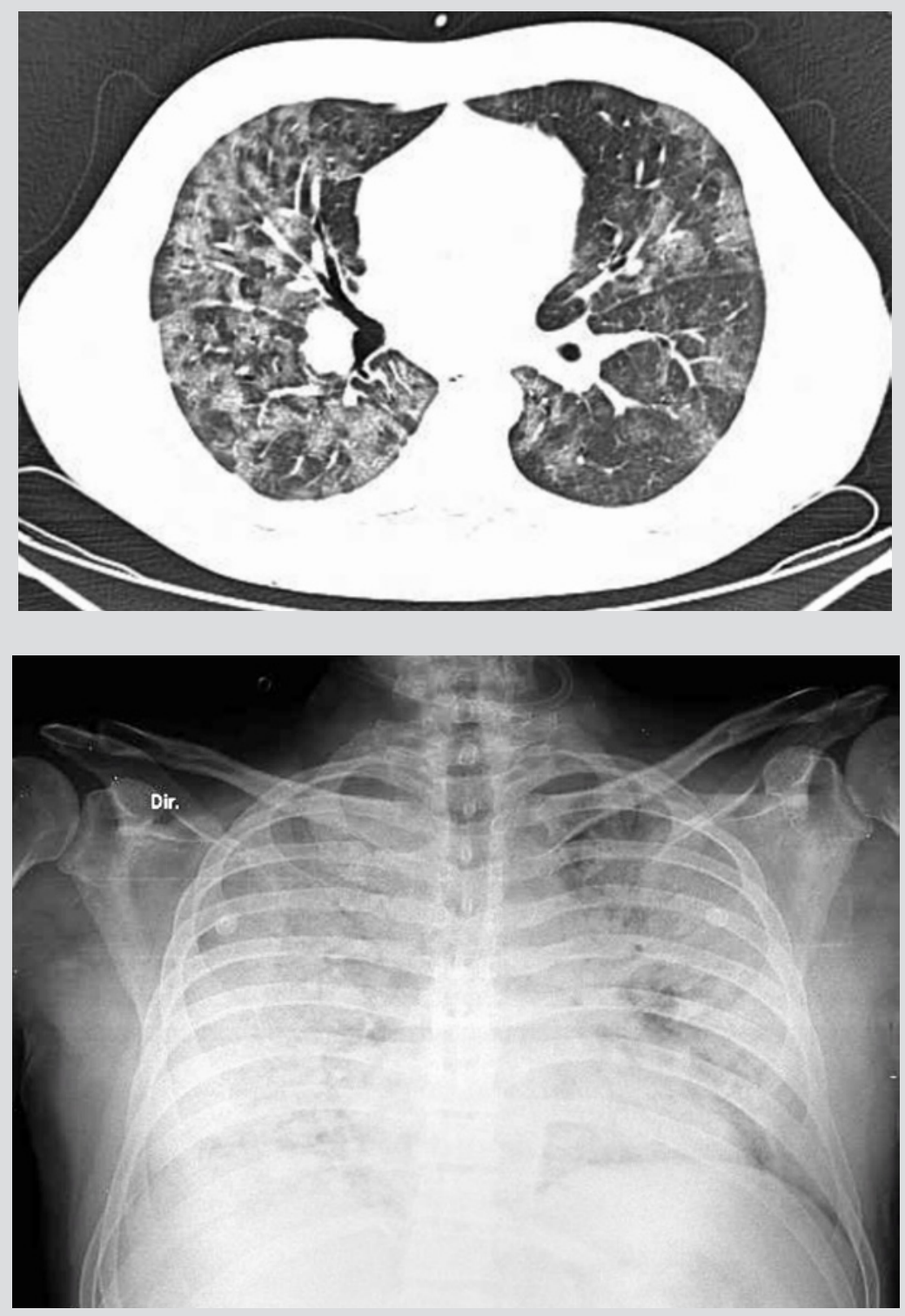

Figure 1. Chest computed tomography showing bilateral ground-glass opacities, with confluent areas of multi-focal mosaic attenuation

Figure 2. X-ray of the thorax showing bilateral diffuse coalescent opacities 
At initial admission (16 February 2020), the patient had a body temperature of $38.5^{\circ} \mathrm{C}$, white blood cell count of $323 \times 10^{\circ} \mathrm{cells} / \mathrm{l}$, lymphocyte percentage of $96 \%$, haemoglobin of $7.6 \mathrm{~g} / \mathrm{l}$, platelet count of 150,000 cells/l, C-reactive protein (high sensitivity test) of $27.75 \mathrm{mg} / \mathrm{l}$ and lactate dehydrogenase of $321 \mathrm{U} / \mathrm{l}$. Plasma IgG, IgM and IgA concentrations were markedly reduced $(0.312,0.33$ and $<0.22 \mathrm{~g} / \mathrm{l}$, respectively) and human intravenous immunoglobulin ( $20 \mathrm{~g}$ ) was administered once daily for 5 days.

After 14 days, the patient had markedly improved regarding oxygen saturation, mechanical ventilation and radiological findings. However, there was a striking dissociation between normal pulse oximetry and persistent low oxygen pressure, prolonging weaning of the patient from mechanical ventilation. We suspected pseudohypoxemia and conducted blood gas analysis at $30 \%$ and $100 \%$ oxygen fractions, with little difference in $\mathrm{PaO}_{2}$ (60-80 mmHg), suggesting our diagnostic hypothesis was correct. Consequently, the patient was weaned to an oxygen fraction of $30 \%$ and maintained an $\mathrm{SpO}_{2}$ of $98-100 \%$, with no evidence of low tissue perfusion.

\section{DISCUSSION}

COVID-19 is caused by a new type of SARS-CoV-2 coronavirus. The elderly and those with underlying conditions are particularly susceptible to the disease. There are few reported cases in the literature of CLL patients with COVID-19, but it can have a major impact on their illness ${ }^{[3]}$. Patients with CLL often have humoral and cellular immune defects, with a strong predisposition to recurrent infections, especially bacterial infections. T-cells, which are responsible for the immune response against viral infection, are depleted in patients with CLL, in particular if they have received chemotherapy ${ }^{[4]}$. These patients may be predisposed to severe infection by SARS-CoV-2, as occurred in our patient. Due to the high risk of COVID-19 infection in patients with CLL, therapy in oligosymptomatic patients should perhaps be delayed as well as in patients with non-life-threatening cytopenias or undergoing less intensive chemotherapy regimens ${ }^{[5]}$.

Pseudohypoxemia is rare and secondary to a high number of metabolically active white blood cells with a high consumption of dissolved oxygen in blood samples. The rate of oxygen consumption by white blood cells is clinically insignificant in most patients with normal blood counts, but in patients with white blood cell counts above $50,000 / \mu \mathrm{l}$ or with severe thrombocytosis, pseudohypoxemia may occur. It is important for clinicians to recognise this condition to avoid diagnostic and therapeutic errors induced by a falsely low oxygen reading [6]. During mechanical ventilation, unrecognized spurious hypoxemia can cause an inappropriate rise in the inspiratory oxygen fraction, thus exposing patients who already are prone to respiratory complications to additional pulmonary oxygen toxicity.

A study systematically investigated the magnitude of spurious hypoxemia in 45 patients with acute leukaemia and hyperleukocytosis, and found a poor correlation between $\mathrm{SaO}_{2}$ and $\mathrm{SpO}_{2}$ in the presence of a white blood cell count above $100,000 \mathrm{~mm}^{3}$, grossly proportional to white blood cell count and time to analysis of blood gases ${ }^{[7] .}$

\section{CONCLUSION}

Our patient demonstrated that a high white blood cell count caused false arterial blood gas measurements of oxygen pressure. Physicians should consider a diagnosis of pseudohypoxemia in patients with white blood cell counts $>50,000 / \mu$ l or severe thrombocytosis, high $\mathrm{SpO}_{2}$, very low $\mathrm{PaO}_{2}$ and no alternative aetiology of hypoxemia. As observed in our patient, pulse oximetry in the context of clinical evidence supporting adequate tissue perfusion may be the most reliable method to assess oxygenation in hyperleukocytosis patients. Early diagnosis of pseudohypoxemia may prevent unnecessary testing and prolonged mechanical ventilation.

\section{REFERENCES}

1. Wang C, Horby PW, Hayden FG, Gao GF. A novel coronavirus outbreak of global health concern. Lancet 2020;395(10223):470-473.

2. He W, Chen L, Yuan G, Fang Y, Chen W, Wu D, et al. COVID-19 in persons with haematological cancers. Leukemia 2020;34:1637-1645.

3. Jin X-H, Zheng KI, Pan K-H, Xie Y-P, Zheng M-H. COVID-19 in a patient with chronic lymphocytic leukaemia. Lancet Haematol 2020;7(4):e351-e352.

4. Melchardt T, Weiss L, Greil R, Egle A. Viral infections and their management in patients with chronic lymphocytic leukemia. Leuk Lymphoma 2013;54(8):1602-1613.

5. Perini GF, Fischer T, Gaiolla RD, Rocha TB, Bellesso M, Teixeira LLC, et al. How to manage lymphoid malignancies during novel 2019 coronavirus (CoVid-19) outbreak: a Brazilian task force recommendation. Hematol Transfus Cell Ther 2020;42(2):103-110.

6. Horr S, Roberson R, Hollingsworth JW. Pseudohypoxemia in a patient with chronic lymphocytic leukemia. Respir Care 2013;58(3):e31-e33.

7. Van de Louw A, Desai RJ, Schneider CW, Claxton DF. Hypoxemia during extreme hyperleukocytosis: how spurious? Respir Care 2016;61(1):8. 